\title{
Heterogeneidades das políticas estaduais de distanciamento social diante da COVID-19: aspectos políticos e técnico- administrativos
}

\author{
Ana Karine Pereira 12 \\ Marilia Silva Oliveira ${ }^{3}$ \\ Thiago da Silva Sampaio ${ }^{4}$ \\ 1 Universidade de Brasília / Centro de Desenvolvimento Sustentável, Brasília / DF - Brasil \\ 2 Universidade de Goiás / Programa de Pós-graduação em Ciência Política e Programa de Pós-graduação em Administração, \\ Goiânia / GO - Brasil \\ 3 Universidade de Brasília / Instituto de Ciência Política, Brasília / DF - Brasil \\ ${ }^{4}$ Universidade Federal do Pampa / Programa de Pós-graduação em Políticas Públicas, São Borja / RS - Brasil
}

\begin{abstract}
Este artigo tem o objetivo de analisar a liderança dos governos estaduais brasileiros na implementação de políticas de distanciamento social para o enfrentamento da disseminação da COVID-19. Pressupõe-se que as políticas de distanciamento social são heterogêneas, apesar da liderança dos governos, ou seja, apresentam certo grau de assimetria nas restrições do funcionamento do comércio e de atividades com potencial de aglomeração de pessoas. Diante disso, foram combinados os debates sobre processo de produção de políticas públicas e sobre autonomia e federalismo, para investigar a influência dos fatores políticos ou técnico-administrativos nas políticas estaduais. Os seguintes procedimentos metodológicos foram utilizados: análise de conteúdo de 134 normativas estaduais; mapeamento do alinhamento político-partidário dos governadores estaduais ao presidente da República; análise dos recursos médico-hospitalares de cada unidade da federação baseada no Cadastro Nacional de Estabelecimentos de Saúde (CNES). O contexto emergencial revelou baixa coordenação interfederativa pelo governo federal, provocando uma competição entre entes federativos e forte liderança estadual na gestão da crise no âmbito local. A pesquisa mostra, por um lado, que as decisões sobre as políticas de distanciamento social não podem ser explicadas por fatores políticos; e por outro, a correspondência entre a capacidade do sistema de saúde local e o nível de rigor das políticas de distanciamento social. Conclui-se que, na atual situação de transtorno social intenso, preferiu-se a racionalidade técnica a barganhas políticas.
\end{abstract}

Palavras-chave: COVID-19; políticas de distanciamento social; coordenação federativa; processo decisório.

\section{Heterogeneidades de las políticas estatales de distanciamiento social frente a la COVID-19: aspectos políticos y técnico-administrativos}

Este artículo tiene como objetivo analizar el liderazgo de los gobiernos de los estados brasileños en la implementación de políticas de distanciamiento social para enfrentar la propagación de la COVID-19. Se parte del supuesto de que, a pesar de la existencia de este liderazgo, las políticas de aislamiento social son heterogéneas, con cierto grado de asimetría en las restricciones al funcionamiento del comercio y de actividades con potencial de aglomeración de personas. Se combinaron debates sobre el proceso de producción de políticas públicas, autonomía y federalismo para investigar si los factores políticos o técnico-administrativos influyen en la naturaleza de estas políticas a nivel estatal. Se utilizaron los siguientes procedimientos metodológicos: análisis de contenido de 134 regulaciones de estados; mapeo del alineamiento político-partidario de los gobernadores estatales con el presidente de la República; y análisis de los recursos médicos y hospitalarios de cada unidad de la federación con base en el Registro Nacional de Establecimientos de Salud. El contexto de emergencia reveló una baja coordinación interfederativa del gobierno federal, lo que provocó la competencia entre entidades federales y el fuerte liderazgo estatal en la gestión de la crisis en ámbito local. Por un lado, el artículo presenta evidencia de que las decisiones sobre políticas de distanciamiento social no pueden explicarse por factores políticos; y, por otro, existe una correspondencia entre la capacidad del sistema de salud local y el nivel de rigor de las políticas de distanciamiento social. Se concluye que, en la actual situación de intenso desorden social, se prefirió la racionalidad técnica a las negociaciones políticas.

Palabras clave: COVID-19; políticas de distanciamiento; coordinación federativa; proceso de toma de decisiones. 


\title{
Asymmetries of state government social distancing policies in the face of COVID-19: political and technical-administrative aspects
}

\begin{abstract}
This article aims to analyze the leadership of Brazilian state governments on lockdown and social distancing policies to keep COVID-19 from spreading. It is assumed that the states' policies on this matter are heterogeneous, and their implementation regarding how commercial activities - and others that potentially involve a large concentration of people - is asymmetric. Therefore, the study observed the debates on policy-making processes and on autonomy and federalism to investigate the influence of political or technical-administrative factors on policies adopted at the state level in Brazil. The methodology used content analysis of 134 state norms, mapping the political-party alignment of state governors to the president, analysis of medical and hospital resources of each federation unit based on the National Register of Health Establishments. The emergency context revealed low inter-federative coordination by the federal government, competition among states, and states leadership in crisis management at the local level. The article presents evidence that state governments' leadership cannot be justified by political party alignment with the president. However, there is a correspondence between both the local health system capacity and the rigor of lockdown and social distancing policies, which indicates that, in an intense social disorder situation, technical rationality was preferable to political bargaining.
\end{abstract}

Keywords: COVID-19; lockdown and social distancing policies; federative coordination; decision-making process.

\section{INTRODUÇÃO}

Em 11 de março de 2020, a Organização Mundial da Saúde (OMS) elevou o estado da contaminação provocada pelo novo coronavírus (SARS-CoV-2), causador da Coronavirus disease 2019 (COVID-19), à pandemia, como resposta à sua rápida disseminação geográfica e à "falta de ação dos governos" (Agência Brasil, 2020). Antes mesmo dessa medida, no Brasil, o governo federal já havia publicado a Portaria n. 188 (2020) do Ministério da Saúde (MS), em 3 de fevereiro de 2020, e a Lei n. 13.979 (2020), de 6 de fevereiro de 20201. A primeira normativa declarou a situação de "Emergência em Saúde Pública de Importância Nacional" (ESPIN); e a segunda, seguindo as orientações da OMS, dispôs sobre as medidas de enfrentamento da emergência em saúde pública, enfatizando a adoção de políticas de distanciamento social, tais como ações de isolamento ${ }^{2}$, de quarentena ${ }^{3}$ e de restrição excepcional e temporária de rodovias, portos e aeroportos. Em março, o MS declarou, por meio da Portaria n. 454 (2020), o estado de transmissão comunitária pela COVID-19 em todo o território nacional.

Nesse cenário, os governos estaduais têm sido bastante ativos em regulamentar, no âmbito local, políticas de distanciamento social. O Distrito Federal foi a primeira unidade da federação a adotar ações restritivas ao suspender, já no dia 11 de março de 2020, eventos com público superior a cinquenta pessoas e as atividades educacionais em escolas, universidades e faculdades das redes de ensino público e privada (Decreto n. 40.509, 2020). Na segunda quinzena de março, todos os estados já haviam editado decretos com o intuito de promover políticas de distanciamento social para conter

\footnotetext{
${ }^{1}$ Esta lei é regulamentada pela Portaria n. 356 (2020), de 11 de março, do Ministério da Saúde.

${ }^{2}$ Segundo a Lei n 13.979 (2020), medidas de isolamento se referem à "separação de pessoas doentes ou contaminadas ou de bagagens, meios de transporte, mercadorias ou encomendas postais afetadas, de outros, de maneira a evitar a contaminação ou a propagação do coronavírus".

${ }^{3}$ De acordo com a referida lei, quarentena é a "restrição de atividades ou separação de pessoas suspeitas de contaminação das pessoas que não estejam doentes, ou de bagagens, contêineres, animais, meios de transporte ou mercadorias suspeitos de contaminação, de maneira a evitar a possível contaminação ou a propagação do coronavírus".
} 
o avanço da pandemia. Apesar da ação rápida e preventiva do governo federal, com destaque para o MS, o presidente da República, Jair Bolsonaro, demorou a se pronunciar em cadeia nacional e, ao fazê-lo apenas no dia 24 de março, entrou em rota de colisão com as medidas já adotadas pelos estados brasileiros e incentivadas pelo MS.

Nesse contexto, os debates em torno das medidas de enfrentamento à epidemia ganharam o caráter de embate entre argumentos políticos e técnicos. Do lado político, o presidente Bolsonaro tem criticado as medidas de quarentena, segundo ele, "impostas" por governadores e prefeitos, com o argumento de que era necessário voltar à normalidade para evitar a paralisação das atividades econômicas e garantir a manutenção dos empregos. O presidente da República tem responsabilizado os governantes dos entes subnacionais pelos efeitos negativos que tais ações poderão ter sobre a economia, o que tem gerado, por um lado, uma onda de manifestações populares de apelo para reabertura do comércio local (Linhares \& Barbon, 2020), e, por outro, críticas contundentes sobre a retomada das atividades, bem como manifestações dos confinados gritando "Fora Bolsonaro" das janelas de suas casas. Bolsonaro tem defendido a tese do distanciamento vertical - sem, contudo, apresentar um plano concreto para viabilizá-la, como a ampliação dos testes para comprovação de contaminação - e o uso da cloroquina, cujos primeiros estudos (Estadão, 2020) não apenas têm apontado a ausência de efeitos significativos no combate à COVID-19, como também seu potencial causador de efeitos colaterais graves.

O lado técnico, representado principalmente pelo ex-ministro da saúde Luiz Henrique Mandetta, enfatizava a necessidade de seguir as orientações da OMS e as evidências científicas, ambas apontando a adoção de políticas restritivas de distanciamento social. Esse conflito culminou na demissão de Mandetta, no dia 16 de março de 2020. Nelson Teich, que substituiu Mandetta, permaneceu à frente do ministério por menos de um mês, sofrendo fortes pressões do presidente Bolsonaro para alterar o protocolo do uso da cloroquina e ampliar as possibilidades do seu uso (Folha de São Paulo, 2020).

Dada a conjuntura, este artigo tem como objeto de análise a liderança dos governos estaduais nas políticas de distanciamento social para o enfrentamento da disseminação da COVID-19. Este fenômeno, importante especialmente para os debates contemporâneos da Ciência Política e Administração Pública, sinaliza para alterações nas relações federativas e para um maior protagonismo dos governos estaduais em uma política de competência comum. Apesar das contestações do presidente Bolsonaro e da Advocacia Geral da União (AGU) (Folha de Pernambuco, 2020), o Supremo Tribunal Federal (STF) garantiu a autonomia dos governos estaduais na determinação do distanciamento social (Pinheiro, 2020), possibilitando, assim, a manutenção da liderança federativa no contexto de crise da saúde pública.

Como pressuposto, considera-se que, apesar da liderança dos governos estaduais, suas políticas de distanciamento social não são homogêneas, havendo certo grau de assimetria nas restrições do funcionamento do comércio e de atividades com potencial de aglomeração de pessoas. Duas perspectivas de análise foram adotadas, investigando, por um lado, a influência de fatores políticos, e, por outro, a de fatores técnico-administrativos na execução das políticas de distanciamento social pelos governos estaduais. Como fator político, levou-se em conta o posicionamento dos governadores estaduais em relação ao presidente da República, como: apoio eleitoral ao seu governo e alinhamento em relação às medidas de distanciamento social. Como fator técnico, foram considerados: a capacidade do Sistema Único de Saúde (SUS), em nível estadual, de lidar com a crise da saúde, tendo por base o número de médicos por habitantes; e o número de leitos e de respiradores disponíveis nas unidades de tratamento intensivo (UTIs). Trabalhamos com as seguintes perguntas: a natureza das políticas de 
distanciamento social estaduais é influenciada por conflitos políticos com o chefe do governo federal, o que limitaria, mesmo que informalmente, a autonomia dos entes subnacionais? O nível de restrição das políticas de distanciamento social adotadas pelos estados é guiado por uma racionalidade técnica, pautada pelas informações disponíveis sobre a capacidade do SUS estadual?

Como estratégia metodológica, foi feita a análise de conteúdo de 134 normativas estaduais publicadas entre o dia 11 de março de 2020 (data do primeiro decreto proveniente de um ente subnacional) e 16 de abril de 2020 (data de demissão do ex-ministro Mandetta). O objetivo da análise foi criar categorias de políticas de distanciamento social e, assim, identificar a natureza dessas políticas em cada estado. A investigação apresenta dados dinâmicos e demonstra a evolução das medidas, segundo as tendências de manutenção das restrições e de flexibilização. $\mathrm{Na}$ análise do fator político, verificou-se: se houve apoio dos governadores estaduais a Bolsonaro nas eleições de 2018; como eles se posicionaram durante o primeiro ano de sua gestão; e se aderiram, ou não, ao discurso contrário ao distanciamento social do presidente. O estudo do fator técnico-administrativo foi pautado na análise dos dados do CNES e dos recursos médico-hospitalares de cada unidade da federação.

Na seção seguinte, combina-se a literatura sobre produção de políticas públicas na área da saúde no Brasil com os debates sobre autonomia e federalismo para fundamentar os pressupostos e as duas hipóteses da pesquisa. Na terceira seção são apresentados e discutidos os dados levantados. A última seção dedica-se às considerações finais.

\section{O PROCESSO DE PRODUÇÃO DE POLÍTICAS PÚBLICAS DE SAÚDE: PRESSUPOSTOS E HIPÓTESES DE PESQUISA}

Parte da produção de políticas públicas envolve a formação da agenda governamental e o processo de formulação e implementação de arranjos institucionais que transformarão as prioridades dos policymakers em realidade. A formação da agenda capta como o governo distribui atenção em determinada área, decidindo quais problemas são mais importantes e merecedores da mobilização governamental (Brasil \& Capella, 2019). Por sua vez, o arranjo institucional é entendido como um conjunto de regras específicas que regulam as relações políticas e sociais em determinado setor ou política (Gomide \& Pires, 2014).

No Brasil, a formação da agenda do setor de saúde tem sido descrita pela literatura a partir da perspectiva de um "equilíbrio pontuado" - em que longos períodos de estabilidade são interrompidos por perturbações ambientais que provocam a difusão de novos entendimentos (Baumgartner \& Jones, 2020) - e pelo "incrementalismo", caracterizado pelos ajustes graduais e pontuais resultantes dos conflitos entre atores e das limitações informacionais e de recursos (Lindblom, 1959; Pierson, 1993, 1994).

Assim, Menicucci (2007) associa o surgimento do SUS a uma ruptura contextual - a redemocratização - que inseriu um entendimento alternativo sobre o papel do Estado na oferta de políticas na área da saúde. Entretanto, o surgimento do SUS também seria explicado por um componente inercial, em que o legado da política acabou culminando em um sistema híbrido: convivência das formas públicas e privadas de assistência à saúde. No período recente, a formação da agenda na área da saúde é marcada por períodos incrementais que são interrompidos por grandes transformações: logo após a redemocratização, a agenda da área concentrou-se na estruturação do sistema - nas formas de financiamento e na relação entre centralização e descentralização -, seguindo- 
se, então, longos momentos de acomodação, rompidos por novas alterações. Por exemplo, de 1993 a 1995, a agenda governamental passou a privilegiar os cuidados primários e preventivos, dando origem a uma reforma do SUS, caracterizada pela diversificação do modelo de assistência e pela incorporação de ações básicas para a população carente (Draibe, 2005; Menicucci, 2014; Menicucci, Costa, \& Machado, 2018; Souza, 2019).

O processo de definição das temáticas prioritárias na área da saúde tem se caracterizado pela desproporcionalidade das atuações dos poderes, havendo forte centralidade no Executivo Federal, especialmente com sua atuação legislativa (Brasil \& Capella, 2019). Neste cenário, o MS tem se sustentado como a autoridade que toma as principais decisões nesta área (Arretche, 2004).

No que se refere à formulação de arranjos institucionais, conforme a Constituição de 1988, o setor de saúde no Brasil compartilha as competências na oferta de serviços entre os entes federativos e há intensa descentralização do SUS (Arretche, 1999; Souza, 2004). Entretanto, a oferta desses serviços pelos estados e municípios não ocorreria de forma automática, envolveria um cálculo sobre os custos da política e a capacidade administrativa e financeira dos entes subnacionais (Arretche, 1999). Diante disso, o governo federal tem assumido uma posição de protagonista na construção de arranjos institucionais de coordenação e cooperação na área social, elaborando um cenário no qual o nível federal concentra as capacidades de normatização e os municípios são importantes atores de implementação (Arretche, 1999; Bichir, 2016; Souza, 2004).

$\mathrm{Na}$ área da saúde, esses arranjos são pautados por instrumentos financeiros e pela normatização do setor pelo MS para a construção de pactos de responsabilização. A centralidade do governo federal na coordenação e indução à cooperação entre os entes federativos é consequência da função governamental de financiar e formular a política nacional de saúde (Arreteche, 2004). A edição de portarias ministeriais representa o principal mecanismo de coordenação das ações nacionais na área e tem como objetivo condicionar o repasse de recursos federais a estados e municípios em alinhamento com os objetivos da política federal (Abrucio, 2005; Arretche, 2004).

Desse modo, na década de 1990, surgiram as Normas Operativas Básicas (NOB) do SUS, racionalizando e condicionando os repasses de recursos para estados e municípios pelo governo federal, além de estabelecerem um sistema de avaliação das políticas de saúde. Abrúcio assinala que, desde a NOB-96, criada na década de 1990, uma importante estruturação aconteceu no SUS: cada instância de governo seria responsável pelo Sistema e os gestores federal e estadual seriam os promotores da “[...] harmonização, modernização e integração do SUS” (Abrucio, 2005, p. 58). A Comissão Intergestores Bipartite (CIB), no nível estadual, e a Comissão Intergestores Tripartite (CIT), no âmbito nacional, foram determinadas como o meio pelo qual essa tarefa seria realizada.

Na primeira década dos anos 2000, foi consolidado o Pacto pela Saúde, uma evolução incremental em relação às outras normas que regulavam as relações federativas no SUS. O Pacto surgiu com o objetivo de promover inovações de gestão e equidade social, além de redefinir responsabilidades coletivas. Apesar de ocorrer numa arena tripartite, a CIT, e contar com importante influência da esfera estadual e municipal, a União deteve a iniciativa de formulação, o que reforça o papel dominante do governo federal no setor de saúde (Menicucci et al., 2018)

Ao analisar a atuação dos entes federativos brasileiros no contexto da pandemia provocada pela COVID-19, é possível relacioná-la a um novo período de ruptura provocada por perturbações externas que alteraram o equilíbrio anterior referente à atuação dos entes federativos, tanto na formação da agenda, como na coordenação entre atores pela normatização do setor da saúde. A perturbação 
externa corresponderia às características e consequências da pandemia: rápida disseminação da doença e consequente esgotamento da capacidade do sistema de saúde, além dos efeitos relacionados à retração econômica. No nível federal, percebe-se um embate entre duas agendas: a adoção de medidas de distanciamento social como a principal política de saúde preventiva em um contexto de ausência de vacinas e tratamentos; e a flexibilização das medidas de distanciamento social a fim de evitar o colapso econômico. Apesar de os especialistas apontarem que esse embate representa uma falsa dicotomia, uma vez que políticas bem-sucedidas de distanciamento social viabilizam uma recuperação econômica mais rápida (Arbix, Veiga, \& Barberia, 2020), o conflito provocou uma paralisia no MS, que não tem tido capacidade de normatizar e coordenar as ações de combate à pandemia no nível nacional. A inação do governo federal forçou os estados, que lidam diretamente com os problemas causados pela pandemia, a assumirem o papel de coordenadores nos seus territórios. Para esse fim, o principal instrumento acionado pelos governadores estaduais tem sido a normatização de políticas de distanciamento social, que orienta a gestão municipal.

Neste contexto, parte-se do pressuposto de que o governo federal perdeu espaço tanto na definição da agenda, como na coordenação entre os entes federativos, forçando os governos estaduais a ocuparem estas funções em um momento de forte crise da saúde pública. Mais do que uma perda passiva de espaço, o posicionamento do governo federal sinaliza a decisão política de não assumir esta responsabilidade baseado em uma visão dualista e não cooperativa do federalismo.

Para investigar se o protagonismo do governo estadual nas políticas de combate à disseminação da COVID-19 é guiado por fatores políticos ou técnico-administrativos, recorre-se à ideia de autonomia, abordada pelos debates de capacidades estatais. De forma geral, o campo de estudos das capacidades estatais investiga como o Estado combina e aciona recursos, processos e relações para resolver problemas sociais concretos e entregar políticas públicas efetivas (Gomide, Pereira, \& Machado, 2017; Gomide \& Pereira, 2018). Os fatores que viabilizam uma atuação satisfatória do Estado variam bastante, podendo envolver recursos informacionais e orçamentários (Wu, Ramesh, \& Howlett, 2015), qualidade da burocracia (Evans \& Rauch, 1999; Skocpol, 1985) e as relações entre burocratas e atores que se localizam fora do Estado (Evans, 1993).

Concorre para a reflexão acerca das capacidades estatais a noção de autonomia. Parte da literatura sobre o assunto considera que a autonomia dos burocratas e dos políticos também contribui para a racionalização e efetividade das ações do Estado. A autonomia dos burocratas é entendida como a não interferência de interesses políticos de curto prazo na sua atuação, predominando a técnica em detrimento de fatores político-eleitorais nas decisões sobre políticas públicas (Bersch, Praça, \& Taylor, 2017; Cingolani, Thomsson, \& Crombrugghe, 2015). A autonomia dos políticos, por sua vez, pode ser entendida como a atuação independente dos líderes políticos em relação aos interesses de grupos sociais dominantes (Geddes, 1994; Skocpol, 1985).

Neste artigo, levou-se em conta a autonomia dos líderes políticos para o entendimento da atuação dos governadores estaduais na gestão da pandemia provocada pela COVID-19. Desse modo, a autonomia dos governadores permite que as análises científicas produzidas pelas burocracias especializadas - tais como a contabilização de novos infectados e de óbitos, e análises sobre a capacidade do sistema de saúde local - guiem as decisões dos líderes estaduais, imperando a técnica em prejuízo de interesses políticos de curto prazo. Seguiu-se o clássico "dilema dos políticos", elaborado por Geddes (1994), segundo o qual os políticos enfrentam um conflito entre suas próprias necessidades imediatas, para a sobrevivência política, e os interesses coletivos de longo prazo. Neste modelo, a autonomia 
dos políticos baseia-se no cálculo estratégico entre o investimento em políticas eficazes na produção de benefício coletivo no longo prazo e o apoio político para múltiplas finalidades, como reeleição, prevenção contra possíveis golpes, aprovação de projetos. A opção pelo apoio político reduziria a autonomia dos líderes políticos à tomada de decisão guiada pela racionalidade técnica - como a tomada de decisão baseada em evidências técnicas.

O debate sobre a produção de políticas públicas e autonomia dos entes subnacionais enfatiza o caráter político das ações dos governos estaduais em um cenário em que o patrimonialismo e o clientelismo dominam o sistema de tomada de decisões (Abrucio, 1998; Hagopian, 1996). Aplicando-se este raciocínio ao contexto de atuação dos governos estaduais na gestão da pandemia da COVID-19, as ações dos governadores seriam influenciadas pela tentativa de construção de apoio político em relação ao presidente da República, com o objetivo de obter apoio eleitoral e evitar possíveis retaliações, por parte da presidência, que desestabilizassem seus mandatos.

A busca por apoio político constitui-se em um dos maiores dilemas das federações: tornar possível a divisão de autoridade entre os estados e o governo federal sem que a rivalidade venha a destruir o potencial de união. Este é o dilema entre autonomia e compartilhamento de autoridade (Souza, 2019), e ele assume várias formas, por exemplo, quando os governos de diferentes esferas culpam uma instância por políticas públicas malsucedidas ou assumem exclusivamente os créditos daquelas bem-sucedidas, gerando oportunismos das esferas de governo.

No contexto da pandemia, a escolha pelo apoio político por parte dos governadores poderia ser interpretada como uma estratégia de escape aos ataques do presidente (Coletta, Caram, \& Uribe, 2020; Pupo \& Resende, 2020) e à culpabilização pelos efeitos econômicos, influenciando os resultados eleitorais futuros, especialmente entre os eleitores bolsonaristas. Outra possível explicação seria o receio de retaliações financeiras acionadas pelo presidente (Congresso em Foco, 2020).

Dado o contexto, a primeira hipótese deste artigo é que quanto maior o alinhamento políticopartidário dos governadores estaduais ao presidente da República, mais flexíveis são as suas políticas de distanciamento social. Isso ocorreria justamente porque a "opção" pelo apoio político limitaria a autonomia dos governadores em seguir as determinações e evidências técnicas produzidas por suas burocracias, como a capacidade do sistema de saúde local e a velocidade de contaminação da população estadual.

No entanto, estudos recentes sobre a gestão estadual de políticas públicas têm apontado a autonomia dos líderes locais e a racionalização desses processos a partir da atuação de uma burocracia profissionalizada, principalmente, proveniente dos governos subnacionais. Tais atores são responsáveis por identificar e inserir as questões locais em uma agenda nacional, independentemente das possíveis amarras centralizantes do modelo federativo brasileiro, as quais restringiriam a autoridade local ao determinar questões sensíveis (Souza, 2019).

Assim, ao estudar as variações nas desigualdades de renda estaduais, Sátyro (2013) aponta que, apesar de diretrizes e políticas redistributivas serem criadas pelo governo federal, as secretarias estaduais têm demonstrado autonomia na realização de alterações que respeitem as necessidades e diferenças regionais. A atuação dos governos locais tem obstáculos impostos pela limitação fiscal. Por esse motivo, Segatto e Béland (2019) pontuam que, no caso específico da saúde pública brasileira, persiste uma descentralização convivendo com resquícios de centralização, cuja base está sobretudo no orçamento público. Por sua vez, Cardoso e Marenco (2019) relevam que a profissionalização dos servidores dos entes subnacionais é um fator decisivo para o alcance de bons resultados nos níveis 
locais, o que indica que o trabalho técnico desses especialistas consegue alcançar o processo decisório de produção de políticas públicas.

Baseado nestes estudos, considera-se que as ações dos governos estaduais podem ser guiadas por fatores técnico-administrativos, e não por influências políticas. De acordo com isso, a segunda hipótese deste artigo prevê que quanto menos estruturado o SUS estadual, mais restritivas são as políticas de distanciamento social, que visam "achatar" a curva de disseminação da doença e permitir que a capacidade do sistema suporte a crise de saúde.

\section{RESULTADOS E DISCUSSÃO}

Por meio do estudo das 134 normativas estaduais, foi possível elaborar três categorias de política de distanciamento social por unidade da federação (vide Quadro 1). A análise de conteúdo dessas normativas teve como ponto central as políticas de restrição do comércio e de atividades com potencial de aglomeração. Assim, não foram incluídas na análise as restrições ao transporte urbano, rural e intermunicipal nem as limitações ao funcionamento de indústrias. É importante esclarecer também que todas as medidas de restrição previam exceções referentes às atividades essenciais determinadas pela Lei n. 13.979 (2020).

Dentre as três categorias de políticas de distanciamento social por unidade da federação aqui elaboradas, tem-se: a categoria "política branda", que engloba estados cujas políticas de distanciamento são pouco detalhadas, apresentam baixo nível de restrição e mantiveram a mesma orientação durante o recorte temporal analisado neste artigo. $\mathrm{O}$ núcleo dessas políticas refere-se à suspensão das atividades educacionais e à proibição de atividades com aglomerações de pessoas.

A categoria "política rigorosa" inclui os estados que, além das políticas brandas, adotaram uma série de ações para suspender ou restringir o comércio local, predominando o fechamento de centros comerciais e limitações do funcionamento de restaurante e bares. Alguns estados incluíram o fechamento de academias e centros estéticos. Estes estados também detalharam quais atividades, locais e serviços com potencial de provocar aglomeração de pessoas deveriam ser limitados ou proibidos de funcionar, a saber: atividades religiosas presenciais, eventos culturais, entre outros. Tendo iniciado suas ações de enfrentamento à pandemia com políticas brandas, com o passar do tempo, entretanto, esses estados passaram a incluir medidas mais restritivas.

A categoria "política rigorosa com tendência à flexibilização" engloba estados cujos primeiros decretos apresentaram natureza bastante restritiva, mas que passaram a permitir, a partir do final do mês de março, o funcionamento de estabelecimentos ou de serviços antes proibidos. Por exemplo, no Rio Grande do Sul, no dia 16 de abril, um novo decreto estadual (Decreto n. 55.128, 2020) permitiu a abertura dos estabelecimentos comerciais mediante fundamentação dos gestores municipais e evidências científicas. O Rio de Janeiro determinou ampla flexibilização com o Decreto n. 47.025 (2020), de 7 de abril, por meio do qual "[...] fica autorizada o funcionamento de estabelecimentos comerciais, de forma irrestrita, nos municípios que não tiveram, até a data da publicação do presente decreto, nenhum caso confirmado de cometimento do coronavírus (COVID-19)". Santa Catarina liberou, em 11 de abril de 2020, o comércio de rua. O Distrito Federal tem passado por medidas graduais, mas constantes, de flexibilização do comércio (vide Quadro 1). 


\section{QUADRO 1 CATEGORIAS DE POLÍTICAS DE DISTANCIAMENTO SOCIAL POR UNIDADE DA FEDERAÇÃO}

\begin{tabular}{|c|c|c|}
\hline $\begin{array}{l}\text { Categoria da } \\
\text { Política de } \\
\text { Distanciamento } \\
\text { Social }\end{array}$ & Ações Principais & Estados \\
\hline Política branda & $\begin{array}{l}\text { Suspensão das atividades educacionais (MS; BA; TO); proibição de atividades com } \\
\text { aglomerações de pessoas (MS; BA; TO); fechamento de parques estaduais e/ou } \\
\text { equipamentos esportivos (MS; T0); fechamento de equipamentos culturais - como } \\
\text { museus e cinemas (BA). }\end{array}$ & MS, TO e BA \\
\hline Política rigorosa & $\begin{array}{l}\text { Proibições/suspensões/fechamento: atividades educacionais (PA; PE; AL; CE; RR; AC; } \\
\text { AM; MG; CE; RN; PR; ES; SE; PB; PI; MA; SP); atividades/eventos com aglomerações de } \\
\text { pessoas (PA; PE;AL; CE; RR; AC; AM; MG; CE; RN; PR; ES; SE; PB; SP; MA; PI); shopping } \\
\text { centers, restaurantes e bares - permite entregas em domicílio e retirada no local (PA; PE; } \\
\text { AL; CE; RR; AC; AM; MG; CE; RN; PR; ES; SE; PB; MA; SP); igrejas/templos ou celebrações } \\
\text { religiosas com público (PA; AL; CE; RR; AC; CE; RN; SE; PB; PI; RR; SP); praias, igarapés } \\
\text { e balneários ou proibição do comércio nesses locais (PA; PE; CE; RN); academias de } \\
\text { ginástica e similares (PA; PE; AL; CE; RR; AC; AM; MG; CE; PR; ES; SE; PB; MA; SP); } \\
\text { equipamentos culturais - como museus e cinemas (PE; AL; CE; RR; AC; AM; MG; CE; } \\
\text { RN; SE; PB; MA; SP); parques estaduais e/ou equipamentos esportivos (MG; RN; Pl; SP); } \\
\text { feiras (PE; CE; AC; MG; CE); salões de beleza e centros estéticos (AC; MG; SE); lojas e } \\
\text { estabelecimentos que pratiquem comércio ou ofereçam serviços privados (AL; CE; AC; } \\
\text { AM; CE; PB; PI); atendimento bancário presencial (RN; ES; PB); casas lotéricas (PB). }\end{array}$ & $\begin{array}{c}\text { SP, AM, RR, } \\
\text { AC, AL, MG, } \\
\text { PA, CE, RN, } \\
\text { PE, PR, ES, } \\
\text { SE, PB, PI e } \\
\text { MA }\end{array}$ \\
\hline $\begin{array}{l}\text { Política rigorosa } \\
\text { com tendência à } \\
\text { flexibilização }\end{array}$ & $\begin{array}{l}\text { Proibições/suspensões/fechamento: atividades educacionais (AP; MT; RO; GO; DF; RJ; } \\
\text { SC; RS); atividades/eventos com aglomerações de pessoas (AP; MT; RO; GO; DF; RJ; SC; } \\
\text { RS); shopping centers, restaurantes e bares - permite entregas em domicílio e retirada } \\
\text { no local (AP; MT; RO; GO; DF; RJ; SC; RS); igrejas/templos ou celebrações religiosas com } \\
\text { público (AP; MT; RO; GO; DF; RJ; SC; RS); praias, igarapés e balneários ou proibição do } \\
\text { comércio nesses locais (AP; MT; RJ); academias de ginástica e similares (AP; MT; DF; } \\
\text { RJ; SC; RS); equipamentos culturais - como museus e cinemas (AP; MT; RO; DF; RJ); } \\
\text { parques estaduais e/ou equipamentos esportivos (AP; MT; DF); feiras (AP; MT); salões de } \\
\text { beleza e centros estéticos (AP; GO; DF); lojas e estabelecimentos que pratiquem comércio } \\
\text { ou ofereçam serviços privados (AP; RO; SC); atendimento bancário presencial (DF). } \\
\text { Flexibilizações/permissões: casas lotéricas (AP; MT; RO; DF); Iojas de conveniências } \\
\text { (AP; MT; DF); shopping centers e galerias comerciais (MT); celebração de velórios (MT); } \\
\text { agências bancárias (MT); hotéis e serviços de hospedagem (RO; SC); feiras (G0; DF, RJ); } \\
\text { floriculturas (DF); lojas de móveis (DF); lojas de eletrodomésticos (DF); funcionamento } \\
\text { de estabelecimentos comerciais, de forma irrestrita, nos municípios que não apresentam } \\
\text { casos confirmados de coronavírus (RJ); comércio de rua (SC); serviços de higiene pessoal } \\
\text { - cabeleireiros e barbeiros (RS); estabelecimentos comerciais, mediante fundamentação } \\
\text { das autoridades municipais (RS). }\end{array}$ & $\begin{array}{c}\text { AP, MT, RO, } \\
\text { GO, DF, RJ, } \\
\text { RS e SC }\end{array}$ \\
\hline
\end{tabular}

Fonte: Elaborado pelos autores. 
Ao analisar do ponto de vista do fator político tais categorias de políticas de distanciamento social estaduais, verificou-se que, dos dezesseis estados brasileiros que implementaram uma política rigorosa de distanciamento social, seis governadores apoiam o governo ou apoiaram a eleição de Bolsonaro; dois mantiveram-se neutros durante as eleições e vêm se posicionando de forma crítica ao governo federal. Dos oito estados que adotaram a política rigorosa com tendência à flexibilização, sete governadores apoiaram a eleição de Bolsonaro ou apoiam o seu governo e um faz oposição a este. Nestes casos, apesar da tendência de flexibilização, as medidas restritivas predominam, sem incorporar as sugestões de Bolsonaro, como as de reabrir escolas. Dos três estados que implementaram política branda de distanciamento social, um governador apoia Bolsonaro, o segundo faz oposição e o terceiro posicionou-se de forma neutra nas eleições, mas sinaliza apoio ao governo do presidente (Vilela, 2018), conforme demonstrado no quadro abaixo.

\section{QUADRO 2 POSICIONAMENTO POLÍTICO DOS GOVERNADORES ESTADUAIS PERANTE 0 PRESIDENTE DA REPÚBLICA X POLÍTICA DE DISTANCIAMENTO SOCIAL}

\begin{tabular}{l|ccc}
\hline Categoria & Apoio a Bolsonaro & Oposição a Bolsonaro & Neutro (2018) \\
\hline $\begin{array}{l}\text { Branda } \\
\text { Rigorosa }\end{array}$ & MS & BA & TO (apoio ao governo) \\
& AC, AM, MG, PR, RR, SP & AL, CE, MA, PB, PE, PI, & ES, PA \\
Rigorosa com tendência à flexibilização & DF, GO, MT, RJ, RO, RS, SC & RN, SE & (críticos ao governo) \\
\hline
\end{tabular}

Fonte: Elaborado pelos autores.

Em relação ao pronunciamento de Bolsonaro no dia 24 de março (Planalto, 2020a), dezenove governadores o criticaram publicamente; destes, sete são seus apoiadores (AC, GO, MS, RJ, RS, SC, SP), conforme o critério aplicado. Um total de seis governadores que apoiam Bolsonaro, ou que apoiaram sua eleição, preferiram não criticar o seu pronunciamento, porém, todos mantiveram as políticas de distanciamento social (AM, DF, MT, MG, PR, TO), dentre as quais quatro eram rigorosas e duas rigorosas com tendência à flexibilização. Apenas dois governadores que apoiam Bolsonaro não se posicionaram em relação ao seu pronunciamento (RO, RR). Todavia um adota política de distanciamento rigorosa e o outro implementa política rigorosa com tendência à flexibilização.

O pronunciamento foi duramente criticado por grande parte dos governadores estaduais, mesmo por aqueles que apoiaram o presidente em sua eleição e que vinham colaborando com seu governo ${ }^{4}$. A crítica mais contundente dentre os apoiadores talvez tenha vindo do governador do estado de São Paulo, João Dória ${ }^{5}$, que lamentou os termos usados pelo presidente e afirmou que este dividia

\footnotetext{
${ }^{4}$ Bolsonaro fez mais dois pronunciamentos à nação; um no dia 31/03 (Planalto, 2020b) e outro no dia 08/04 (Planalto, 2020c). Decidiuse focar no pronunciamento do dia 24/03 (Planalto, 2020a) por ter suscitado mais críticas na sociedade e entre os governadores. Nos outros pronunciamentos, Bolsonaro adotou um tom mais brando e reconheceu a gravidade da crise, mas teceu críticas às medidas de isolamento e reforçou o uso da cloroquina para tratamento do vírus.

${ }^{5}$ O governador de São Paulo foi apoiador de Bolsonaro nas eleições de 2018 e durante o ano de 2019. Todavia, em fevereiro de 2020, Bolsonaro rompeu com Dória por questões eleitorais e pelo confronto de opiniões em relação à cobrança de imposto estadual sobre combustíveis.
} 
o país com seu posicionamento. Bolsonaro respondeu brutalmente à crítica de Dória e o acusou de oportunista eleitoral $(\mathrm{G} 1,2020)$. Outro rompimento drástico foi operado pelo governador do estado do Goiás, Ronaldo Caiado, que chamou de irresponsável o discurso presidencial e criticou fortemente a posição de Bolsonaro de "responsabilizar outras pessoas por um colapso econômico", sem assumir sua própria responsabilidade na crise em que o país se encontra (Boghossian, 2020).

Ao analisar o posicionamento de Bolsonaro em relação às medidas estaduais de contenção da contaminação pelo SARS-Cov-2 em território nacional, observa-se, por um lado, que os governadores atuaram de forma autônoma, desconsiderando as orientações do presidente da República e seguindo as recomendações técnicas do MS e as evidências técnicas fornecidas pelas secretarias estaduais. Retomando o "dilema dos políticos" (Geddes, 1994), observa-se que, em uma situação de forte crise sanitária e de incertezas, ao realizar o cálculo estratégico para guiar suas ações na gestão da pandemia, os líderes estaduais não priorizaram o apoio político de curto prazo. Este resultado enfraquece os estudos tradicionais, segundo os quais a gestão de políticas públicas no nível subnacional é marcada por barganhas políticas e fisiologismo (Hagopian, 1996).

Por outro lado, também se percebe a ocorrência de um dos dilemas federativos destacados por Souza (2019): autonomia versus compartilhamento de autoridade. O presidente responsabiliza diretamente os governadores estaduais pelo agravamento da crise econômica, eximindo o governo federal de parte de sua responsabilidade. O discurso de Bolsonaro tem peso e sentido real para os milhares de brasileiros que perderam seus empregos em virtude da pandemia e se envolve de ostensivo caráter político, pois distingue o presidente dos demais representantes do poder executivo estadual que não apoiam suas orientações. O comportamento acusador de Bolsonaro pode ter efeitos negativos para a autonomia dos políticos que continuarem a tomar decisões calcadas pela técnica, expondo pontos nevrálgicos da política partidária e eleitoral. O presidente impõe rivalidades e retaliações àqueles que dele discordam, corroendo o potencial de união e impedindo a cooperação entre os entes federativos num momento de emergência sanitária e econômica.

Do ponto de vista técnico-administrativo, relacionado à capacidade do sistema de saúde local, três fatores concorreram para o colapso do sistema de saúde em vários países: a velocidade de propagação do SARS-Cov-2, o tempo médio de internação de cada paciente e a demanda por suprimentos médicos. No Brasil, para evitar o colapso em meio ao avanço da epidemia, os estados iniciaram uma corrida sem planejamento, competindo entre si e com o governo federal por insumos, sobretudo, por ventiladores pulmonares (Amorim, 2020). No caso da disputa por suprimentos, a saída aventada por parte dos secretários de saúde foi, por um lado, solicitar ao MS a centralização da compra dos equipamentos médico-hospitalares, e, por outro, apelar às medidas de conscientização da população com o intuito de retardar o colapso.

A falta de suprimentos aliou-se ao baixo quantitativo de profissionais da saúde. Por exemplo, uma UTI para adultos requer, no mínimo, um especialista em medicina intensiva para atuar como responsável técnico ${ }^{6}$. No entanto, dos 4.500 intensivistas que o país possui, cerca de $50 \%$ encontramse em apenas vinte cidades ${ }^{7}$.

\footnotetext{
${ }^{6}$ Portaria n. 3.432 (1998), de 12 de agosto, do Ministério da Saúde.

${ }^{7}$ As seguintes cidades concentram o maior número de intensivistas: São Paulo (15,2\%); Rio de Janeiro (6,3\%); Belo Horizonte (3,2\%); Salvador (2,8\%); Recife (2,3\%); Fortaleza (2,1\%); Goiânia (1,8\%); Porto Alegre (1,7\%); Campinas (1,7\%); Brasília (1,6\%); Curitiba (1,5\%); Belém (1,3\%); Natal (1,2\%); Manaus (1,2\%); Vitória (1,0\%); Ribeirão Preto (1,0\%); João Pessoa (1,0\%); Niterói (1,0\%); Florianópolis $(0,9 \%)$ e Teresina ( $0,9 \%)$ (Dados compilados obtidos no CNES-DataSUS).
} 
O cada um por si que se instalou escancara a baixa articulação do governo federal com os governadores, contrariando o seu papel tradicional, na área da saúde, de coordenação e cooperação com os entes subnacionais. Diante disso, cabe aqui analisar o cenário de cada Estado e identificar se as ações são mais rígidas proporcionalmente a um contexto em que a infraestrutura médico-hospitalar mostra-se mais frágil para suportar a demanda da COVID-19. Na Tabela 1 é possível identificar a proporção de UTIs, respiradores e intensivistas por habitante de cada Estado.

Com relação às UTIs, a OMS estabelece o padrão de uma UTI para cada dez mil habitantes. Nesse quesito, o DF é a unidade da federação com melhor estrutura; enquanto Maranhão, Tocantins, Pará, Amapá, Amazonas, Acre e Roraima não atendem a proporção mínima definida pela OMS. A distorção entre as unidades da federação repete-se na distribuição de respiradores. Enquanto São Paulo tem um para cada 28.137 habitantes, o Maranhão tem um para cada 262.044 habitante.

\section{TABELA 1 PROPORÇÃO DE EQUIPAMENTOS E NÚMERO DE ÓBITOS POR UF}

\begin{tabular}{|c|c|c|c|c|c|c|}
\hline U.F. & Tipo de Política & UTI & Intensivistas & Respiradores & $\begin{array}{c}\text { Casos } \\
\text { Acumulados }\end{array}$ & $\begin{array}{c}\text { Óbitos } \\
\text { Acumulados }\end{array}$ \\
\hline Acre & Rigorosa & 15205,8 & 40088,0 & 5802,2 & 110 & 5 \\
\hline Alagoas & Rigorosa & 8646 & 98157,6 & 5855,0 & 89 & 5 \\
\hline Amapá & $\begin{array}{l}\text { Rigorosa com tendência à } \\
\text { flexibilização }\end{array}$ & 14334,4 & 120818,7 & 8997,1 & 362 & 9 \\
\hline Amazonas & Rigorosa & 15181,7 & 67944,2 & 4610,2 & 1719 & 124 \\
\hline Bahia & Branda & 6729,9 & 79535,1 & 4489,3 & 951 & 30 \\
\hline Ceará & Rigorosa & 7270,8 & 80105,9 & 4267,3 & 2386 & 124 \\
\hline Distrito Federal & $\begin{array}{l}\text { Rigorosa com tendência à } \\
\text { flexibilização }\end{array}$ & 3270,4 & 41878,7 & 1405,7 & 716 & 20 \\
\hline Espírito Santo & Rigorosa & 4918,8 & 33488,8 & 2706,2 & 754 & 22 \\
\hline Goiás & $\begin{array}{l}\text { Rigorosa com tendência à } \\
\text { flexibilização }\end{array}$ & 5610,2 & 55701,2 & 4035,9 & 318 & 16 \\
\hline Maranhão & Rigorosa & 11831,4 & 262043,7 & 6581,6 & 695 & 37 \\
\hline Mato Grosso & $\begin{array}{l}\text { Rigorosa com tendência à } \\
\text { flexibilização }\end{array}$ & 4455,8 & 49778,1 & 2478,3 & 156 & 5 \\
\hline Mato Grosso do Sul & Branda & 7572,2 & 59127,4 & 3037,1 & 131 & 5 \\
\hline Minas Gerais & Rigorosa & 6629,7 & 52922,0 & 3358,5 & 958 & 33 \\
\hline Pará & Rigorosa & 13655,3 & 92503,9 & 5896,4 & 438 & 24 \\
\hline Paraíba & Rigorosa & 8604,1 & 61817,3 & 4353,3 & 165 & 24 \\
\hline Paraná & Rigorosa & 4471,6 & 56885,4 & 3022,5 & 832 & 41 \\
\hline Pernambuco & Rigorosa & 4954,4 & 67780,6 & 3052,4 & 1683 & 160 \\
\hline
\end{tabular}




\begin{tabular}{|c|c|c|c|c|c|c|}
\hline U.F. & Tipo de Política & UTI & Intensivistas & Respiradores & $\begin{array}{c}\text { Casos } \\
\text { Acumulados }\end{array}$ & $\begin{array}{c}\text { Óbitos } \\
\text { Acumulados }\end{array}$ \\
\hline Piauí & Rigorosa & 8943,2 & 69643,1 & 7273,8 & 91 & 8 \\
\hline Rio de Janeiro & $\begin{array}{l}\text { Rigorosa com tendência à } \\
\text { flexibilização }\end{array}$ & 3795,3 & 34323,9 & 2210,3 & 3944 & 300 \\
\hline Rio Grande do Norte & Rigorosa & 7525,4 & 49392,3 & 4292,4 & 400 & 20 \\
\hline Rio Grande do Sul & Rigorosa & 6457 & 50565,5 & 3275,9 & 780 & 19 \\
\hline Rondônia & $\begin{array}{l}\text { Rigorosa com tendência à } \\
\text { flexibilização }\end{array}$ & 7224,5 & 52271,3 & 3822,0 & 76 & 3 \\
\hline Roraima & Rigorosa & 24230,4 & 46597,0 & 3985,3 & 142 & 3 \\
\hline Santa Catarina & $\begin{array}{l}\text { Rigorosa com tendência à } \\
\text { flexibilização }\end{array}$ & 6882,6 & 44227,1 & 3268,6 & 884 & 29 \\
\hline São Paulo & Rigorosa & 4650,5 & 28136,7 & 2462,1 & 11568 & 853 \\
\hline Sergipe & Rigorosa & 9014,5 & 63852,7 & 4264,7 & 48 & 4 \\
\hline Tocantins & Branda & 12582,9 & 112347,6 & 4824,7 & 29 & 1 \\
\hline
\end{tabular}

Fonte: Elaborada pelos autores com base em dados do DataSUS e MS (2020).

O número de casos e óbitos não mantém relação direta com a estrutura médico-hospitalar de cada Estado. Eles se distribuem harmonicamente pelo país: quanto maior a população, maior a incidência de casos e óbitos ${ }^{8}$. A quantidade de leitos, UTIs e respiradores passa a ter influência direta no número de óbitos a partir do momento em que o sistema entra em colapso. A ampliação do sistema, durante a pandemia, esbarra em barreiras econômicas, logísticas e na baixa oferta de recursos humanos, como o já destacado caso dos médicos intensivistas. As políticas adotadas pelos governadores tinham como justificativa abrandar este quadro.

\section{TABELA 2 MÉDIA DE EQUIPAMENTOS MÉDICO-HOSPITALARES E DE CASOS POR TIPO DE POLÍTICA}

\begin{tabular}{lccccc} 
Tipo de Política & UTI & Intensivistas & Respiradores & $\begin{array}{c}\text { Casos } \\
\text { Acumulados }\end{array}$ & $\begin{array}{c}\text { Óbitos } \\
\text { Acumulados }\end{array}$ \\
\cline { 1 - 5 } & Média & Média & Média & Média & Média \\
\hline Branda & 8961,7 & 83670,0 & 4117,0 & 370,3 & 12,0 \\
Rigorosa & 9540,6 & 71877,9 & 4415,3 & 1344,6 & 88,6 \\
Rigorosa com tendência à flexibilização & 6510,5 & 56999,9 & 3745,4 & 922,3 & 54,6
\end{tabular}

Fonte: Elaborada pelos autores com base em DataSUS e Ministério da Saúde (16/04/2020).

\footnotetext{
${ }^{8}$ A correlação entre a população e o número de casos é de 0,896 , e entre o número de óbitos é de 0,873 .
} 
A Tabela 2 aponta que os estados que adotaram medidas mais rigorosas são os menos preparados para o surto: em média, eles possuem uma UTI para cada 9.540,6 habitantes. Já aqueles que optaram por medidas brandas contam com uma UTI para cada 8.961,7, e os que implementaram ações rigorosas com tendência à flexibilização dispõem de uma UTI para 6.510 habitantes. Esta mesma tendência repete-se relativamente à média de respiradores. Ainda, os estados que adotaram políticas mais rigorosas são os que apresentam maior quantidade de casos e óbitos acumulados; no outro extremo, estão os estados que adotaram políticas brandas, com a menor média de casos e óbitos no período analisado.

Esses dados evidenciam que a liderança dos governadores em relação às políticas de distanciamento social no contexto da pandemia da COVID-19 é guiada por evidências técnicas, o que demonstra autonomia dos líderes estaduais. Corroboram, portanto, estudos recentes que apontam que a produção de políticas públicas nos entes subnacionais é marcada pela autonomia dos líderes locais e pela racionalização do processo a partir da influência técnica de uma burocracia profissionalizada (Cardoso \& Marenco, 2019; Sátyro, 2013).

\section{CONSIDERAÇ̃̃ES FINAIS}

No Brasil, a crise na área de saúde provocada pela COVID-19 exigiu respostas rápidas dos líderes políticos e gestores, em um contexto de forte disputa entre argumentos técnicos e políticos para guiar as ações públicas. Seguindo os estudos que aplicam a noção de "equilíbrio pontuado" para analisar a produção de políticas públicas na área de saúde no Brasil, argumenta-se que as perturbações socioeconômicas geradas pela pandemia da COVID-19 romperam com o equilíbrio anterior caracterizado pela concentração múltipla de funções no governo federal: formação da agenda na área, coordenação entre os entes subnacionais e indução da cooperação entre eles (Brasil \& Capella, 2019; Menicucci, 2014; Souza, 2019). Assim, no cenário atual, os governadores assumiram essas funções ao normatizar as políticas de distanciamento social e ao estabelecer regras que orientam e coordenam as ações dos municípios. Diante dessa inovação, produzida no contexto de forte crise sanitária, este artigo investigou se a liderança dos governos estaduais é guiada por fatores técnico-administrativos ou por influências políticas.

Não foram encontradas evidências que sustentem, no recorte temporal adotado, a hipótese da relação entre a flexibilização das políticas de distanciamento social e o maior alinhamento políticopartidário dos governadores estaduais ao presidente da República. Assim, verificou-se um número significativo de governadores politicamente alinhados ao Governo Bolsonaro que adotaram política de distanciamento social restritiva. Apesar de a maioria dos governadores que efetivou políticas rígidas com tendência a flexibilização ser composta de apoiadores do presidente da República, as medidas de flexibilização acionadas por este grupo não incorporam as demandas do presidente por reabertura ampla de atividades econômicas e educacionais.

Os dados apresentados aqui enfraquecem os estudos tradicionais que relacionam a gestão dos entes subnacionais a barganhas políticas e a práticas clientelistas (Abrucio, 1998; Hagopian, 1996). Todavia é considerável a guerra travada por Bolsonaro contra os governadores estaduais que mantêm as políticas de distanciamento, uma vez que as acusações proferidas pelo presidente da República são graves o suficiente para produzir perdas eleitorais e afetar o grau de autonomia dos governadores em continuarem a tomar decisões orientadas pela técnica e no sentido de conter a disseminação do 
vírus e a sobrecarga do sistema de saúde. O comportamento presidencial impõe um dos dilemas mais potentes às federações, o da autonomia versus a partilha de autoridade, com implicações diversas.

Exortam-se estudos que busquem compreender as peculiaridades das perturbações provocadas pela pandemia e sua influência no comportamento dos governadores, examinando a padronização ou a excepcionalidade dos procedimentos observados na área da política da saúde. Outrossim, é importante que pesquisas monitorem a flexibilização das políticas de distanciamento nos estados, relacionando-as aos seus reais motivos, se por ameaça econômica, por pressão política ou por outros motivos considerados.

Quanto à hipótese de que quanto menos estruturado o SUS estadual, mais restritivas são as políticas de distanciamento social, o artigo apresenta evidências de que há correspondência entre a capacidade do sistema de saúde local e o nível de rigor das políticas de distanciamento social. Estes dados corroboram estudos que têm apontado para a racionalização e autonomia da gestão dos entes subnacionais (Cardoso \& Marenco, 2019; Sátyro, 2013).

Em conjunto, os dados levantados revelam que, diante do "dilema dos políticos" (Geddes, 1994), os governadores optaram pelo investimento em capacidades e racionalização da política, uma vez que levaram em consideração as informações técnicas produzidas por burocracias especializadas em detrimento do apoio político do presidente da República. A opção dos governadores lhes conferiu autonomia para agir segundo as recomendações científicas apresentadas pela OMS e pelas burocracias brasileiras (federal e estaduais), em lugar de se submeterem a barganhas políticas contrárias às evidências científicas.

Aplicada a um recorte temporal específico, esta análise engloba apenas a gestão do ex-Ministro Mandetta, caracterizada pela forte defesa de soluções técnicas e científicas pelo MS. Após esse período, é possível perceber algumas mudanças em relação às tipologias de políticas de distanciamento social adotadas pelos estados. Assim, alguns destes que se enquadravam na categoria "política rigorosa” têm sinalizado a possibilidade de flexibilização e reabertura a partir do mês de maio, como é o caso do estado de São Paulo. Há também estados que adotavam "políticas rigorosas com tendência à flexibilização", como Santa Catarina, que radicalizaram a reabertura do comércio nas semanas seguintes ao recorte temporal adotado neste artigo, convertendo suas políticas de rigorosas a brandas, justamente em um momento de ascensão do número de contaminações e óbitos provocados pela COVID-19.

As relações entre a mudança de liderança do MS e as posturas dos governadores instigam novas pesquisas que reconfigurem a incidência dos fatores políticos e técnicos na elaboração das políticas de saúde. Igualmente importante é a investigação de dois temas: o da qualidade das burocracias estaduais que contribuem para a liderança dos governadores na elaboração de políticas de combate à disseminação da COVID-19; e o referente à perda de capacidade de o MS normatizar o setor e, consequentemente, viabilizar uma coordenação federativa robusta desde o governo federal.

Assim, estudos futuros podem se debruçar sobre as seguintes questões: os estados que possuem burocracias mais profissionalizadas na área da saúde viabilizaram um melhor desempenho das políticas estaduais de distanciamento social? Como a atuação do presidente da República reduziu a autonomia do MS para normatizar e coordenar os entes subnacionais no combate à pandemia da COVID-19? 


\section{REFERÊNCIAS}

Abrucio, F. L. (1998). Os Barões da Federação: os governadores e a redemocratização brasileira. São Paulo, SP: Hucitec, 1998.

Abrucio, F. L. (2005). A Coordenação Federativa no Brasil: a experiência do período FHC e os desafios do governo Lula. Revista de Sociologia Política, 24, 41-67.

Agência Brasil. (2020, 11 de março). Organização Mundial da Saúde declara pandemia de coronavírus. Atualmente, ao menos 115 países têm casos da doença. Recuperado de https://agenciabrasil.ebc.com.br/ geral/noticia/2020-03/organizacao-mundial-dasaude-declara-pandemia-de-coronavirus

Amorim, F. (2020, 26 de março). Governo centraliza estoque de respiradores e gera atrito com estados. UOL (Notícias). Recuperado de https://noticias. uol.com.br/politica/ultimas-noticias/2020/03/26/ governo-centraliza-estoque-de-respiradores-e-geraatrito-com-estados.htm

Arbix, G., Veiga, J. P., \& Barberia, L. (2020, 30 de abril). Falta de coordenação entre o governo federal e estados enfraquecem a política de distanciamento social. A flexibilização sem critérios pode agravar a pandemia. Covid-19: Políticas Públicas e as Respostas da Sociedade (Rede de Pesquisa Solidária, boletim 4). São Paulo, SP: Políticas Públicas \& Sociedade.

Arretche, M. T. S. (1999). Políticas sociais no Brasil: descentralização em um Estado Federativo. Revista Brasileira de Ciências Sociais, 14(40), 111-141.

Arretche, M. T. S. (2004). Federalismo e políticas sociais no Brasil: problemas de coordenação e autonomia. São Paulo Em Perspectiva, 18(2), 17-26.

Baumgartner, F. R., \& Jones, B. D. (Ed.). (2002). Policy dynamics. Chicago, Illinois: University of Chicago Press.

Bersch, K., Praca, S., \& Taylor, M. M (2017). State Capacity, Bureaucratic Politicization, and Corruption in the Brazilian State. Governance: an International Journal of Policy, Administration, and Institutions, 30(1), 105-124.

Bichir, R. M. (2016). Novos instrumentos de coordenação federativa: reflexões a partir do Programa Bolsa Família. Revista Brasileira de Políticas Públicas e Internacionais, 1, 49-78.

Boghossian, B. (2020, 25 de março). Caiado rompe com Bolsonaro e diz que não respeitará decisões do presidente. Folha de São Paulo. Recuperado de https://www1.folha.uol.com.br/poder/2020/03/ caiado-rompe-com-bolsonaro-e-diz-que-naorespeitara-decisoes-do-presidente.shtml

Brasil, F., \& Capella, A. C. (2019). A dinâmica da atenção governamental sobre as políticas de saúde no Brasil: equilíbrio pontuado nas primeiras décadas pós-redemocratização (1986-2003). Saúde e Sociedade, 28(3), 80-96.

Cardoso, A. L. R., \& Marenco, A. (2019). Qualidade Burocrática e Performance Estatal: desvendando a caixa preta do município. Administração Pública e Gestão Social, 11(4), 1-21. Recuperado de https:// periodicos.ufv.br/apgs/article/view/6318

Cingolani, L., Thomsson, K., \& Crombrugghe, D. (2015). Minding Weber more than ever? The impacts of state capacity and bureaucratic autonomy on development goals. World Development, 72, 191-207.

Colleta, R. D., Caram, B., \& Uribe, G. (2020, 14 de maio). É guerra, tem que jogar pesado com governadores, diz Bolsonaro a empresários. Folha de São Paulo. Recuperado de https://www1.folha. uol.com.br/poder/2020/05/e-guerra-tem-quejogar-pesado-com-governadores-diz-bolsonaro-aempresarios.shtml

Congresso em Foco. (2020, 03 de junho). Bolsonaro veta repasse de $R \$ 8,6$ bilhóes para estados e municípios. Recuperado de https://congressoemfoco. uol.com.br/governo/bolsonaro-veta-repasse-de-r86-bilhoes-para-estados-e-municipios/

DataSUS. (2020, 06 de maio). Cadastro Nacional de Estabelecimentos de Saúde. Recuperado de http:// cnes2.datasus.gov.br/

Decreto Distrital n. 40.509 de 12 de março de 2020, do Governo do Distrito Federal. (2020). Dispõe sobre as medidas para enfrentamento da emergência de saúde pública de importância internacional decorrente do novo coronavírus e dá outras providências. Brasília, DF. Recuperado de http://www.sinj.df.gov.br/SINJ/ Norma/ad0fae78af5f4e50b46c7357b7ee8597/ Decreto_40509_11_03_2020.html

Decreto Estadual n. 55.128, de 19 de março de 2020, do Governo do Rio Grande do Sul. (2020). Declara estado de calamidade pública em todo o território do Estado do Rio Grande do Sul para fins de prevenção e de enfrentamento à epidemia causada 
pelo COVID-19 (novo Coronavírus), e dá outras providências. Recuperado de https://cremers.org.br/ wp-content/uploads/2020/03/19.03.2020-Decreton\%C2\%BA-55128-do-governo-do-Estado.pdf

Decreto Estadual n. 1415, de 22 de março de 2020, do Governo do Amapá. (2020). Altera o Decreto Estadual $n^{\circ} 1.414$ de 19 março de 2020, que dispõe sobre restrições de funcionamento para o fim de combater a disseminação do novo Coronavírus (COVID-19) no território do Estado do Amapá. Recuperado de https://www.legisweb.com.br/legislacao/?id=391457

Decreto Estadual n. 24.891, de 23 de março de 2020, do Governo de Rondônia. (2020). Altera e acrescenta dispositivos do Decreto ${ }^{\circ} 24.887$, de 20 de março de 2020. Recuperado de http://www.rondonia.ro.gov. br/publicacao/decreto-no-24-891/

Decreto Estadual no 425, de 25 de março de 2020, do Governo do Mato Grosso do Sul. (2020). Consolida as medidas temporárias restritivas às atividades privadas para prevenção dos riscos de disseminação do Coronavírus (COVID-19) e dá outras providências. Recuperado de https://www.legisweb.com.br/ legislacao/?id=391758

Decreto Estadual n. 29.583, de $1^{\circ}$ de abril de 2020, do Governo do Rio Grande do Norte. (2020). Consolida as medidas de saúde para o enfrentamento do novo coronavírus (COVID-19) no âmbito do Estado do Rio Grande do Norte e dá outras providências. Recuperado de https://www.legisweb.com.br/ legislacao $/$ id $=392200$

Decreto Estadual no 9.645, de 03 de abril de 2020, do governo do Goiás. (2020). Altera o Decreto n. 9.633 , de 13 de março de 2020. Recuperado de https://legisla.casacivil.go.gov.br/pesquisa legislacao/103080

Decreto Estadual n. 47.025, de 07 de abril de 2020, do Governo do Rio de Janeiro. (2020). Dispõe sobre a liberação de atividade comercial em municípios sem notificação de cometimento do Covid-19, e dá outras providências. Recuperado de https://www.legisweb. com.br/legislacao/?id=392689

Decreto n. 64.881, de 20 de março de 2020, do Governo de São Paulo. (2020). Decreta quarentena no Estado de São Paulo, no contexto da pandemia do COVID-19 (Novo Coronavírus), e dá providências complementares. Recuperado de https://www.al.sp. gov.br/norma/193361
Draibe, S. M. (2005). Ciclos de reformas de políticas públicas em ambiente de consolidação da democracia: a experiência brasileira recente de reforma dos programas sociais. Campinas, SP: Unicamp.

Estadão. (2020, 04 de junho). Em novo estudo, cloroquina não apresenta efeitos significativos no combate à covid-19. Recuperado de https://saude. estadao.com.br/noticias/geral,em-novo-estudocloroquina-nao-apresenta-efeitos-significativos-nocombate-a-covid-19,70003324318

Evans, P. (1993). O Estado como problema e solução. Lua Nova: Revista de Cultura e Política, 28-29, 107-157.

Evans, P., \& Rauch, J. E. (1999, outubro). Bureaucracy and growth: a cross-national analysis of the effects of "Weberian" state structures on economic growth. American Sociological Review, 4(5), 748-765.

Folha de São Paulo. (2020, 15 de maio). Após ultimato sobre cloroquina, Teich pede demissão do Ministério da Saúde. Recuperado de https://www1. folha.uol.com.br/equilibrioesaude/2020/05/aposultimato-sobre-cloroquina-teich-pede-demissaodo-ministerio-da-saude.shtml

Folha de Pernambuco. (2020, 14 de abril). Governo Bolsonaro recorre ao STF para que estados e municípios sigam regras federais de isolamento. Recuperado de https://www.folhape.com.br/POLITICA/2193GOVERNO-BOLSONARO-RECORRE-STFPARA-QUE-ESTADOS-MUNICIPIOS-SIGAMREGRAS-FEDERAIS-ISOLAMENTO/137219/

Geddes, B. (1994). Politician's Dilemma: Building State Capacity in Latin America. Berkeley, CA: University of California Press.

Gomide, A. A., Pereira, A. K., \& Machado, R. A. (2017). Capacidade estatal e a pesquisa científica: contribuições do dossiê temático. Sociedade e Cultura, 20, 3-12.

Gomide, A., \& Pereira, A. K (2018). Capacidades estatais para políticas de infraestrutura no Brasil contemporâneo. Revista de Administração Pública, 52(5), 935-955.

G1. (2020, 25 de março). Doria e Bolsonaro discutem em reunião de governadores. Governador de São Paulo fez duras críticas ao presidente por pronunciamento minimizando coronavírus. Recuperado de https:// g1.globo.com/jornal-nacional/noticia/2020/03/25/ doria-e-bolsonaro-discutem-em-reuniao-degovernadores.ghtml 
Hagopian, F. (1996). Traditional politics and regime change in Brazil. Cambridge, UK: Cambridge University Press.

Lei n. 13.979, de 6 de fevereiro de 2020. (2020). Dispõe sobre as medidas para enfrentamento da emergência de saúde pública de importância internacional decorrente do coronavírus responsável pelo surto de 2019. Recuperado de http://www.planalto.gov. br/ccivil_03/_ato2019-2022/2020/lei/L13979.htm

Lindblom, C. (1959). The Science of Muddling Through. Public Administration Review, 19(2), 79-88.

Linhares, C., \& Barbon, J. (2020, 18 de abril). Carreata em SP mira Doria e Maia em meio a pedidos de intervenção militar. Folha de São Paulo. Recuperado de https://www1.folha.uol.com.br/ poder/2020/04/carreata-em-sp-mira-doria-e-maiaem-meio-a-pedidos-de-intervencao-militar.shtml

Menicucci, T. M. G. (2007). Os Argumentos Analíticos: A Perspectiva Histórica e Institucional. In Menicucci, T. M. G., Público e Privado na Política de Assistência à Saúde no Brasil: Atores, processos e trajetória (Cap. XX, pp. 21-56). Rio de Janeiro, RJ: Editora Fiocruz.

Menicucci. T. M. G. (2014). Cooperação e coordenação na implementação de políticas públicas: as relações intergovernamentais na regionalização da assistência à saúde. In Anais do 90 Encontro da $A B C P$, Brasília, DF.

Menicucci, T. M. G., Costa, L. A., \& Machado, J. A. (2018). Pacto pela saúde: aproximações e colisões na arena federativa. Ciência e Saúde Coletiva, 23(1), 29-40.

Pierson, P. (1993). When effect becomes cause: policy feedback and political change. World Politics, 45(1), 595-628.

Pierson, P. (1994). Dismantling the Welfare State? Reagan, Thatcher, and the Political Retrenchment. Cambridge, UK: Cambridge University press.

Pinheiro, R. (2020, 16 de abril). STF reconhece competência de estados e municípios em regras de isolamento. Rádio Senado (Notícias). Recuperado de https://www12.senado.leg.br/radio/1/noticia/stfreconhece-competencia-concorrente-de-estados-dfmunicipios-e-uniao-no-combate-a-covid-19

Pires, R. R. C., \& Gomide, A. A. (2014). Capacidades estatais e democracia: a abordagem dos arranjos institucionais para análise de políticas públicas. In Pires, R. R. C., Gomide, A. A. (Eds.), Capacidades estatais e democracia: arranjos institucionais de políticas públicas (v. 1, pp. 15-30). Brasília, DF: Ipea.

Planalto. (2020a, 24 de março). Pronunciamento do presidente da República, Jair Bolsonaro, em Cadeia de Rádio e Televisão, em 24/03/2020. Pronunciamento apresentado por Jair Bolsonaro. [Brasília, DF], 2020. 1 vídeo (4min 58seg). Publicado pelo canal do Palácio do Planalto. Recuperado de https://www. youtube.com/watch?v=Vl_DYb-XaAE

Planalto. (2020b, 31 de março). Pronunciamento do presidente da República, Jair Bolsonaro, em Cadeia de Rádio e Televisão, em 31/03/2020. Pronunciamento apresentado por Jair Bolsonaro. [Brasília, DF], 2020. 1 vídeo (7min 29seg). Publicado pelo canal do Palácio do Planalto. Recuperado de https://www. youtube.com/watch?v=16RR2rG_AKA

Planalto. (2020c, 08 de abril). Pronunciamento do presidente da República, Jair Bolsonaro, em Cadeia de Rádio e Televisão, em 08/04/2020. Pronunciamento apresentado por Jair Bolsonaro. [Brasília], 2020. 1 vídeo (5min 10seg). Publicado pelo canal do Palácio do Planalto. Recuperado de https://www.youtube. $\mathrm{com} /$ watch? $\mathrm{v}=\mathrm{x} 04 \mathrm{OKkxT2Tc}$

Portaria n. 188, de 3 de fevereiro de 2020, do Ministério da Saúde. (2020). Declara Emergência em Saúde Pública de importância Nacional (ESPIN) em decorrência da Infecção Humana pelo novo Coronavírus (2019-nCoV). Recuperado de http:// www.in.gov.br/en/web/dou/-/portaria-n-188-de-3de-fevereiro-de-2020-241408388

Portaria n. 356, de 11 de março de 2020, do Ministério da Saúde. (2020). Dispõe sobre a regulamentação e operacionalização do disposto na Lei $\mathrm{n}^{\circ} 13.979$, de 6 de fevereiro de 2020, que estabelece as medidas para enfrentamento da emergência de saúde pública de importância internacional decorrente do coronavírus (COVID-19). Recuperado de http:// www.in.gov.br/en/web/dou/-/portaria-n-356-de-11de-marco-de-2020-247538346

Portaria n. 454, de 20 de março de 2020, do Ministério da Saúde. (2020). Declara, em todo o território nacional, o estado de transmissão comunitária do coronavírus (covid-19). Recuperado de http://www. in.gov.br/en/web/dou/-/portaria-n-454-de-20-demarco-de-2020-249091587 
Portaria n. 3.432, de 12 de agosto de 1998, do Ministério da Saúde. (2020). Estabelece critérios de classificação para as Unidades de Tratamento Intensivo - UTI. Recuperado de http://bvsms.saude.gov.br/bvs/ saudelegis/gm/1998/prt3432_12_08_1998.html

Pupo, F., \& Resende, T. (2020, 03 de junho). Bolsonaro veta repasse de $\mathrm{R} \$ 8,6$ bi para estados e municípios combaterem coronavírus. Folha de São Paulo. Recuperado de https://www1.folha.uol.com. br/mercado/2020/06/bolsonaro-veta-repasse-der-86-bi-para-estados-e-municipios-combateremcoronavirus.shtml

Sátyro, N. G. D. (2013). Política estadual e desigualdade: por que alguns estados redistribuem mais do que outros? Dados, 56(3), 497-530.

Skocpol, T. (1985). Bringing the State Back In: Strategies of Analysis in Current Research. In P. Evans, D. Rueschemeyer, \& T. Skocpol (Eds.), Bringing the State Back In (pp. 3-38). Cambridge, UK: Cambridge University Press. Recuperado de https://doi.org/10.1017/CBO9780511628283.002

Segatto, C. I., \& Béland, D. (2019, junho). Federalism and decision making in health care: the influence of subnational governments in Brazil. Policy Studies, 1-19. Recuperado de https://doi.org/10.1080/0144 2872.2019.1634187

Souza, C. (2004). Governos locais e gestão de políticas sociais universais. São Paulo em Perspectiva, 18(2), 27-41.

Souza, C. (2019, 17 de junho). Coordenação, uniformidade e autonomia na formulação de políticas públicas: experiências federativas no cenário internacional e nacional. Caderno de Saúde Pública, 35(supl. 2), e00046818. Recuperado de https://doi.org/10.1590/0102-311x00046818

Vilela, P. R. (2020, 28 de outubro). Bolsonaro recebeu apoio de 15 dos 27 governadores eleitos. Agência Brasil. Recuperado de https://agenciabrasil. ebc.com.br/politica/noticia/2018-10/bolsonarorecebeu-apoio-de-15-dos-27-governadoreseleitos

Wu, X., Ramesh, M., \& Howlett, M. (2015). Policy capacity: a conceptual framework for understanding policy competences and capabilities. Policy and Society, 34(3-4), 165-171.

\section{Ana Karine Pereira}

https://orcid.org/0000-0002-7282-6122

Doutora em Ciência Política pela Universidade de Brasília (UnB); Professora adjunta do Centro de Desenvolvimento Sustentável da Universidade de Brasília (UnB); Professora permanente dos programas de Pós-graduação em Ciência Política (PPGCP) e em Administração (PPGADM) da Universidade Federal de Goiás (UFG). E-mail: ana.pereira@unb.br

\section{Marília Silva Oliveira}

https://orcid.org/0000-0002-1055-781X

Doutora e pós-doutoranda em Ciência Política pelo Instituto de Ciência Política da Universidade de Brasília (UnB). E-mail: mariliasoliveira@gmail.com

\section{Thiago da Silva Sampaio}

https://orcid.org/0000-0003-1178-0746

Doutor em Ciência Política pela Universidade Federal de Minas Gerais (UFMG); Professor adjunto do Programa de Pós-graduação em Políticas Públicas da Universidade Federal do Pampa (UNIPAMPA).

E-mail: thiagosampaio@unipampa.edu.br 